\title{
MÚSICA NA SALA DE AULA: RECURSO DIDÁTICO PARA O ENSINO DE LÍNGUA PORTUGUESA
}

COSTA, Fabiana Claudia Viana ${ }^{1}$

FARIA, Mariana Alves ${ }^{2}$

\begin{abstract}
RESUMO: Este trabalho apresenta um estudo da música como recurso didático para as aulas de Língua Portuguesa (interpretação, produção de textos e gramática), a partir de uma pesquisa realizada em uma Escola Estadual de Ensino Médio, objetivando oferecer subsídios para que o aprendizado de língua portuguesa, especificamente do ensino médio, torne-se mais instigante para o aluno em sala de aula, considerando que muitos professores se preocupam em aprimorar suas metodologias de ensino e em envolver o aluno no conteúdo de língua materna.
\end{abstract}

Palavras-Chave: Interação. Prática de Ensino de Língua Portuguesa. Ensino/Aprendizagem. Música.

SUMMARY: This work presents a study of music as a didactic resource for Portuguese Language (interpretation, production of texts and grammar), from a research carried through in a State School of Average Education, objectifying to offer subsidies for classes of Portuguese Language, specifically of average education, it becomes provocative for the pupil in classroom, because many professors are worried in improving their methodologies education and involving the student in the first language content.

Keywords: Interaction. Practical of Education of Portuguese Language. Education/Learning. Music.

\section{INTRODUÇÃO}

Comparando o ensino da antiguidade com o atual, pode ser observado, de acordo com

Manacorda (1989), que, naquele tempo, o ensinamento era, primeiramente, passado do pai para o filho, e as pouquíssimas escolas que existiam eram freqüentadas apenas por filhos de nobres, e o ensino, não só no Egito como também na Grécia e em Roma, era voltado para a arte de falar bem (retórica), com o objetivo de o aprendiz aprender a dominar e comandar. Já no ensino atual, as escolas são muitas e inúmeros são os alunos também, tendo a população oportunidade de aprender e aprimorar seus conhecimentos, pois, no ensino de hoje, existem diversas práticas para melhor aplicar o conteúdo e ajudar no aprendizado, possibilitando ao aluno conviver e interagir com o mundo que o cerca.

A escolha pelo ensino médio se deu por ser o último estágio do aluno na escola antes de ingressar no ensino superior, colocando-se como o período em que o aluno procura por mais respostas relacionadas a sua realidade sócio-histórica, numa busca (in)consciente de sua formação e de sua personalidade.

1 Doutoranda em Lingüística pelo Instituto de Estudos da Linguagem, na Universidade Estadual de Campinas, Professora de lingüística do Curso de Letras da Faculdade de Filosofia, Ciências e Letras de Ituverava e Professora substituta do Departamento de Letras da Universidade Federal de São Carlos.

2 Graduada em Letras pela Faculdade de Filosofia, Ciências e Letras de Ituverava e pós graduanda em Educação Ambiental e Responsabilidade Social pela Faculdade de Agronomia Dr. Francisco Maeda. 
A possibilidade do uso de outras linguagens em sala de aula só é possível, neste trabalho, por conceber-se a linguagem como um processo de interação, considerando que, quando se faz uso da língua, não apenas se traduz ou exterioriza o pensamento, ou transmite informações a outrem, mas sim realiza ações, age, atua sobre o interlocutor, seja ele ouvinte ou leitor. A linguagem é, pois, o lugar de interação humana, de interação comunicativa pela produção de efeitos de sentido entre interlocutores, em uma dada situação de comunicação e em um contexto sócio-histórico e ideológico. Para isso, os usuários da língua ou interlocutores interagem enquanto sujeitos que ocupam lugares sociais e "falam" e "ouvem" desses lugares de acordo com formações imaginárias (imagens) que a sociedade estabeleceu para tais lugares sociais. É o dialogo em sentido amplo que caracteriza a linguagem (TRAVAGLIA, 1998).

A música, base para o desenvolvimento da proposta prática aqui apresentada, é o recurso que, quando bem aplicado à prática da linguagem, resulta em um trabalho de leitura, interpretação, compreensão e discussão de textos, e não apenas como um pano de fundo para o ensino de gramática nas aulas de português ou para restringir o estudo a estilos de gêneros musicais.

\title{
1 BRASIL E REALIDADE SOCIAL: PROPOSTA PRÁTICA
}

Foi formulada uma atividade em que será trabalhada a música "Meu País" da dupla de cantores e compositores Zezé de Camargo e Luciano, para leitura, interpretação, reflexão e produção de texto. Vejamos:

MEU PAÍS

\author{
Zezé de Camargo e Luciano \\ Aqui não falta sol \\ Aqui não falta chuva \\ A terra faz brotar qualquer semente \\ Se a mão de Deus \\ Protege e molha o nosso chão \\ Por que será que ta faltando pão? \\ Se a natureza nunca reclamou da gente \\ Do corte do machado, a foice, o fogo ardente
}

Se nessa terra tudo que se planta dá

Que é que há, meu país?

O que é que há?

Tem alguém levando lucro

Tem alguém colhendo o fruto

Sem saber o que é plantar

Tá faltando consciência

Tá sobrando paciência

Tá faltando alguém gritar 


\section{Feito um trem desgovernado \\ Quem trabalha tá ferrado \\ Nas mãos de quem só engana \\ Feito mal que não tem cura \\ Estão levando à loucura \\ O país que a gente ama \\ Feito mal que não tem cura \\ Estão levando à loucura \\ O Brasil que a gente ama}

O objetivo dessa atividade, pensada para alunos do ensino médio, é trabalhar em sala de aula com textos diversos, como por exemplo, o filme: Pelle, O Conquistador e a música Meu País. Como desenvolvimento da atividade, veja o seguinte percurso:

- inicialmente, solicitar aos alunos que perguntem em casa, na vizinhança e no bairro, o que consideram como miséria, o que seria a causa e quais seriam as soluções;

- discutir com os alunos acerca do tema miséria, sobre o que coletaram e o que eles entendem e pensam a respeito desse assunto; como, segundo eles, a miséria é (re)tratada pelos meios de comunicação e outros pontos que possam surgir na discussão;

- apresentar aos alunos o filme Pelle, O Conquistador, antecipando o que poderão encontrar para, então, transmitir o filme, com duração de 120 minutos;

- entregar fotocópias da música Meu País e colocar para os alunos ouvirem;

- distribuir os alunos em grupos para que discutam a música e o filme, a partir da temática exposta; orientá-los em seus grupos;

- colocar a sala em círculo para a sociabilização das opiniões dos alunos, com contribuições e questionamentos do professor, a fim de provocar discussões e reflexões sobre o assunto, bem como interagir com os mais tímidos;

- realizar um "fechamento" do assunto, ressaltando os pontos relevantes explicitados pelos alunos; e,

- propor uma produção de texto escrito, a partir da tipologia trabalhada em sala de aula.

Essa atividade será avaliada conforme critérios pré-estabelecidos pelo professor e pelos alunos, tanto na produção escrita quanto na produção oral (coleta de informações, debates, participação, discussões).

O desenvolvimento dessa proposta foi a partir do pressuposto de que, no momento em que o professor trabalha a música com o aluno em sala de aula, ele se torna um mediador da construção do conhecimento dos alunos. Ao deixá-los à vontade, para o pensamento e a imaginação fluirem, pela interação com os outros alunos, formando e construindo suas idéias, contribui para que o aluno forme suas próprias idéias em relação ao tema. Com isso, o professor 
auxilia, também, a exercitar o pensamento na formação e construção da personalidade desses alunos, trabalhando com temas sociais, culturais, políticos etc, dentro das disciplinas.

\section{EM BUSCA DE UM LEITOR E UM PRODUTOR DE TEXTOS REAIS: PRESSUPOSTOS TEÓRICOS}

No ensino médio, há, de acordo com a proposta pedagógica do MEC - (Ministério da Educação), muitas práticas para auxiliar o ensino do professor de Língua Portuguesa. São planos de estudo de forma interdisciplinar, sugerindo que o processo pedagógico tenha como base:

O trabalho sistematizado com leituras de publicações diversas, além do livro didático, selecionando temas e construindo objetivos de estudos capazes de integrar os conhecimentos trabalhados nas respectivas áreas de conhecimento e interdisciplinarmente; envolvendo os alunos nesse processo de escolha; valorizando a cultura e o contexto local referenciados na cultura global, levando-se em conta os interesses, a realidade e os projetos pessoal/sociais do aluno;

A produção coletiva dos textos, de acordo com a identidade da escola, dos alunos e da região, de forma a ultrapassar a perspectiva homogeneizante imposta pelo livro didático.(BRASIL, 2006)

Acrescentar a música nas práticas pedagógicas possibilita ao professor de língua materna desenvolver nos alunos a leitura, reflexão e produção de textos, de maneira menos enfadonha, utilizando, por exemplo, rádio (para ouvir a música), fotocópias (para fazer leitura), na TV e DVD.

Segundo o Mec (BRASIL, 2006), no Ensino Médio, a perspectiva interdisciplinar e a proposta pedagógica são vastas, como já citadas, mas, no entanto, ainda há, entre a classe de educadores, insatisfação na questão do aprendizado, desejando que, em sala de aula, haja, entre os alunos, o prazer em aprender.

Essa insatisfação dos professores surge não só da questão do ensino, mas da realidade social, como afirma (ALMEIDA, 1999, p.14-15)

[...]miséria social e a miséria da língua confundem-se. Vemos que conseguir falar, hoje, já é uma proeza fantástica para a multidão que não desfruta das riquezas econômicas (que ela mesma produz). Não meramente grunhir uns sons para suprir necessidades básicas; falar mesmo, dizer o mundo, suas vidas, seus desejos, prazeres; dizer coisas para transformar, dizer o seu sofrimento e suas causas, dizer o que fazer para mudar, lutar.

Em observações de campo, nota-se que a realidade social e lingüística se pautam tal como a afirmação acima; mesmo assim, considera-se que a escola pode ser o lugar de melhoria da realidade, a partir do trabalho com diferentes formas de linguagem em que o aluno não se sinta preso ou impedido de "dizer o mundo" e que não considere a escola como um planeta 
distante da realidade atual.

Ao considerar as multiplicidades tecnológicas em sala de aula, aqui representadas pela música, Suassuna (1995) cita Braga (1979), num de seus artigos na questão do ensino e dos meios de comunicação de massa. Segundo ela,

[...]essa profusão de códigos, linguagens e mensagens que nos circundam em cada instante e em cada canto de nosso cotidiano, não está nos imbecilizando, mas criando novas formas e estruturas de pensamento, outros modos de ver-apalpar o mundo e interagir com ele. Ao invés de vermos esses outros processos de leitura como inimigos viscerais da linguagem verbal, creio que teríamos de buscar enxergar as possíveis riquezas de seus entrecruzamentos.

Para Orlandi (1988), a leitura é produzida em condições determinadas, dentro de um contexto sócio-histórico que deve ser levado em conta. Ela define a leitura como atribuição de sentidos, usada, indiferentemente, tanto para a escrita quanto para a oralidade, pois, se há linguagem, há leitura, sendo responsável pela vida intelectual. Afirma ainda que o leitor não interage com o texto (sujeito/objeto), mas com outros sujeitos (leitor imaginário, autor...). A interação da leitura que a autora diz existir é o jogo entre o leitor imaginário e o leitor real. Para ela, os domínios lingüísticos, pedagógicos e sociais estão integrados ao mesmo tempo.

De acordo com a autora (op. cit.), os sentidos que podem ser lidos em um texto podem ou não estar contidos nele. Então, o processo de ler é bastante complexo e não se limita ao imediato. Saber ler, para ela, é saber o que o texto diz e o que ele não diz; e o sentido do texto está determinado pela posição que ocupam aqueles que o produzem (emitentes e leitores). Define dois tipos de leitura: a) parafrástica: que se caracteriza pelo reconhecimento (reprodução) do sentido dado pelo autor; e, b) leitura polissêmica: que se caracteriza pela atribuição de múltiplos sentidos do texto. Há, então, a "pluralidade das leituras", ou seja, a possibilidade de ler um texto de várias maneiras.

\section{ANÁLISE DOS DADOS}

A pesquisa de campo foi desenvolvida em duas salas de aula de uma escola estadual da cidade de Ituverava-SP; cuja escolha se deu a partir da realização de Estágio Supervisionado, uma das exigências da Faculdade para a conclusão do curso de Letras. A princípio, foi aplicado um questionário ${ }^{3}$ com dez perguntas para os alunos e dez perguntas para os professores. As perguntas feitas aos alunos, como pode ser observado, eram relacionadas ao gosto musical, às atividades feitas, no dia-a-dia, com música e se já fora desenvolvida alguma atividade a partir do uso da música em sala de aula. As perguntas feitas aos professores eram, também, sobre o gosto musical; se já haviam desenvolvido atividades com músicas, qual fora o resultado e o desempenho dos alunos no decorrer do bimestre.

A partir da análise dos dados, observou-se que um dos professores, aqui chamado de 
Informante A [IA], professor de Português, mostrou menos interesse pelo assunto, e os alunos de sua sala de aula [ALA], de ensino médio, também se mostraram desinteressados. Já o outro professor - Informante B [IB] -, professor de Português e Inglês mostrou-se interessado em aprimorar sua técnica, inclusive com música, e, por conseguinte, seus alunos [ALB], também do ensino médio, mostraram-se mais descontraídos, seguros e interessados na matéria. Veja, abaixo, os recortes das respostas dos professores:

QUESTÃO 5: Quais atividades foram desenvolvidas a partir da música?

[IA] Produção de texto. Reflexão sobre determinado tema.

[IB] Vocabulário. Verbos. Pronuncia. Estudo do texto.

QUESTÃO 6: Qual foi o resultado? Eles gostaram?

[IA] Razoável. Alguns.

[IB] Os alunos gostam de música. O resultado foi o esperado.

QUESTÃO 7: Qual a reação dos alunos durante o trabalho? Qual foi o desempenho dos educandos no decorrer do bimestre com relação a trabalhos feitos com a utilização da música?

[IA] Alguns gostam, outros não.

Nem sempre os resultados são positivos, muitos confundem a música com bagunça.

[IB] Reação normal.

Foi observado, também, que tanto o IA quanto o IB se mostraram neutros e com certa recusa em querer descrever sua prática ou sugestão para ajudar no aprendizado de língua portuguesa. Houve aí um silenciamento para a QUESTÃO 8, O que você sugeriria como um novo método de trabalho com música?

Percebe-se certa resistência dos professores informantes frente à pesquisa, sobretudo em responder ao questionário, visto que as respostas foram, quase sempre, diretas, sem descrições que pudessem auxiliar no entendimento das atividades e dos resultados.

A pesquisa feita com os alunos mostra que quase todos já participaram de atividades com músicas em sala de aula, relacionadas ao conteúdo, e muitos disseram que gostaram da atividade e se interessam por este tipo de ensino (música unida à matéria), como pode ser observado nos recortes dos alunos ALB:

\footnotetext{
[ALB] Muito boas, a gente aprende melhor.

Otímo, Bom Ajuda no estudo.

Boas pois ela nos ajudam a ter

criatividade e fazer atividades novas.
}

Em contrapartida, alguns alunos do IA mostraram-se insatisfeitos com o trabalho realizado a partir da música, sobretudo pelo estilo musical utilizado, vejamos:

\author{
[ALA] Ruim. \\ Muito chato (tédio). \\ Chatas, porque não gosto de música clássica.
}


Estas colocações explicitam que a música escolhida pelo professor, ópera, música clássica e marchinhas de carnaval, não condizia com o gosto musical dos alunos.

Quando questionados sobre o gosto musical, a maioria das respostas dos alunos caminhou para as músicas mais tocadas na maioria das rádios, colocando-os num espaço de identificação com os outros colegas, por se tratar, principalmente, de músicas "do momento", como o rap, o funk, o hip-hop, o pagode. Com isso, o trabalho em sala de aula, com música, precisa estar pautado, dentre outras coisas, no gosto do aluno. Não que dessa forma possa ser afirmado que o trabalho do professor precisa estar sempre, e tão somente, baseado nos estilos musicais preferidos dos alunos, mas que haja um planejamento a fim de que os diversos gêneros musicais perpassem pelo espaço pedagógico, e não somente os clássicos, por exemplo.

É preciso que a comunidade de educadores esqueça as diferenças e unam-se para colocar este "otimismo" em prática, por que a escola é o local em que é preciso depositar não só esperança e otimismo para a construção do futuro, mas sim, é preciso construir e transformar o hoje. Para isso, a educação, enquanto processo, metodologia e currículo, precisa ser (re)vista a partir das novas exigências dos meios de comunicação social, seja pelo conteúdo, seja pela forma.

A partir das análises das respostas dos alunos, explicitadas anteriormente, quando a música faz referência ao contexto sócio-histórico do aluno, aproximando-o do texto e quebrando as barreiras de um mundo desconhecido para um mundo já conhecido, contribui para o desenvolvimento das idéias do aluno na produção textual, amenizando, como disse Almeida (1999), a miséria social e a miséria da língua, porque a música, sobretudo a atual, já está contextualizada na historia de vida do aluno.

Quando o estilo de música utilizado é originário de uma época mais antiga, o professor deve contextualizar o aluno na origem do estilo, na época histórica, no ritmo. Dessa forma, o ensino estaria pautado numa prática que coloca o aluno frente a diversas realidades culturais, sociais e históricas, fazendo com que ele tenha a chance de expressar suas idéias, dizer o mundo, suas vidas... dizer coisas para transformar, dizer o seu sofrimento e suas causas, dizer o que fazer para mudar, lutar (ALMEIDA, 1999, p.14-15).

Os educadores não podem estar aquém das mudanças tecnológicas, pois, como afirma Geraldi (1996), o fato da humanidade estar na "era da comunicação" faz, muitas vezes, com que o jovem não tenha expressão própria. Isso acontece porque, infelizmente, o aluno faz uma leitura apenas parafrástica.

$\mathrm{Na}$ procura para reavivar a chama do prazer em ler e produzir um texto sobre algo que foi lido e refletido, pode-se registrar que esta prática não é absoluta, nem única, mas dela evidencia-se a vontade em querer mudar, transformar as aulas de Língua Portuguesa de simples transferência de informação para compreensão, reflexão e conhecimento.

A escola é um centro de convivência social e é nela que os professores de Língua Portuguesa, podem contribuir para a melhoria de uma sociedade que, raramente, freqüenta as bibliotecas, praticam leituras críticas de fato, tanto mulheres e homens profissionais, quanto os não profissionais. 


\section{REFERÊNCIAS}

ALMEIDA, M.J. Ensinar Português?. In: GERALDI, J. W. O texto na sala de aula. São Paulo: Ática, 1999.

BRASIL. Ministério da Educação e Cultura. PARÂMETROS Curriculares Nacionais. Disponível em: <http://www.mec.gov.br>. Acesso em: 24 ago. 2006.

FERREIRA, A.B.H. Minidicionário da Língua Portuguesa. 3.ed. Rio de Janeiro: Nova Fronteira, 1993.

GARCIA, P. Musicoterapia. Disponível em: $<$ http://www.musicoterapia.psc.br $>$. Acesso em: 16 jul.2006.

GERALDI, J.W. Linguagem e ensino: exercício de militância e divulgação. Campinas: Mercado das Letras/Associação de Leitura do Brasil, 1996.

LOPES, H.V. Os direitos humanos e o ensino da língua. In.: MURRIE, S. F. (org.). O ensino de português: do primeiro grau à universidade. 5.ed. São Paulo: Contexto, 2001.

MANACORDA, M.A. História da educação: da antiguidade aos nossos dias. São Paulo: Cortez, 1989.

MARCUSCHI, L. A. Leitura e compreensão de Texto Falado e Escrito como Ato Individual de uma Prática Social. IN: ZILBERMAN, R.; SILVA, E. (Org.) Leitura: perspectivas interdisciplinares. Campinas: Ática, 1988.

MESERANI, S. O Intertexto escolar: sobre leitura, aula e redação. São Paulo: Cortez, 1995.

ORLANDI, E. Discurso e leitura. 4.ed. Campinas: Cortez, 1988.

ROMÃO, L.M.S.; PACIFICO, S.M.R. Era uma vez uma outra história: leitura e interpretação na sala de aula. São Paulo: Difusão Cultural do Livro, 2006.

SILVA, Y.J. Meios de comunicação e educação: o rádio, um poderoso aliado. IN: CIAPPINI, L. (Org.) Outras linguagens na escola: publicidade, cinema e TV, rádio, jogos, informática. 4.ed. São Paulo: Cortez, 2004.

SUASSUNA, L. Ensino de língua portuguesa: uma abordagem pragmática. Campinas: Papirus, 1995.

TRAVAGLIA, L. C. Gramática e interação: uma proposta para o ensino de gramática nos $1^{\circ}$ e $2^{\circ}$ graus. 4.ed. São Paulo: Cortez, 1998. 